\title{
Atropelamentos de vertebrados na Floresta Nacional de Carajás, Pará, Brasil
}

\author{
Fabiano GUMIER-COSTA1 ${ }^{1}$, Carlos Frankl SPERBER ${ }^{2}$
}

RESUMO

Vários pesquisadores têm avaliado impactos de estradas. Estes podem envolver aspectos paisagísticos, degradação do solo, poluição do ar e impactos sobre a fauna, como atropelamentos. Na estrada Raimundo Mascarenhas, que atravessa a Floresta Nacional de Carajás (ca. 400 mil hectares), há intenso tráfego de veículos automotores. O objetivo deste trabalho foi testar se há diferenças entre trechos da estrada, em três escalas espaciais; se há alteração ao longo dos anos; se alguns táxons são mais freqüentemente atropelados, e se a freqüência de atropelamentos aumenta com a precipitação mensal. Analisamos a freqüência de atropelamentos de vertebrados de abril/2003 até outubro/2006 ao longo dos $25 \mathrm{~km}$ iniciais da estrada. Registramos 155 atropelamentos. $\mathrm{O}$ número de atropelamentos diminui ao longo dos anos $(\mathrm{P}=0,01)$, e com a distância do início da estrada $(\mathrm{P}=0,0002)$. Serpentes (Ophidia) e gambás Didelphis marsupialis foram mais atropelados (7,5/ano), seguidos de aves, raposas Cerdocyon thous, quatis Nasua nasua, roedores (Rodentia), e não identificados (4,9/ano); cuíca Marmosops sp., tapeti Sylvilagus brasiliensis, guariba Alouatta sp., irara Eira barbara, jabuti Geochelone sp., lagartos (Lacertilia) e macaco prego Cebus apella (1/ ano). Não houve relação significativa entre o número mensal de atropelamentos e a precipitação mensal.

PALAVRAS-CHAVE: Impacto ambiental, fauna silvestre, Carajás, Amazônia, tráfego, veículos automotores.

\section{Roadkills of vertebrates in Carajas National Forest, Para, Brazil}

\section{ABSTRACT}

Several researchers have evaluated impacts of highways. These can involve landscape aspects, soil degradation, air pollution, and impacts upon wildlife, such as roadkills. At the Raimundo Mascarenhas highway, that crosses the Carajás National Forest (ca. $400.000 \mathrm{ha}$ ), there is intense traffic of automotive vehicles. The aim of this work was to test if there were differences among higway sections on three spatial scales; if there was alteration along the years; if some taxa suffered more frequently roadkills; and if roadkill frequency increased with monthly precipitation. We analysed roadkill frequency of vertebrates from April/2003 to Octobre/2006 along the first $25 \mathrm{~km}$ of the highway. We registered 155 roadkills. The number of roadkills diminished along the years $(\mathrm{P}=0,01)$, and with distance from the beginning of the highway $(\mathrm{P}=0,0002)$. Snakes (Ophidia) and opossum Didelphis marsupialis presented higher roadkill numbers (7,5/year), followed by birds (Aves), crab-eating fox Cerdocyon thous, coati Nasua nasua, rodents (Rodentia), and non identified (4,9/year); opossum Marmosops sp., brazilian rabbit Sylvilagus brasiliensis, black howler monkey Alouatta sp., tayra Eira barbara, tortoise Geochelone sp., lizards (Lacertilia) e capuchin monkey Cebus apella (1/year). There was no significant relation between monthly roadkill numbers and monthly precipitation.

KEY WORDS: Environmental impact, wildlife fauna, Amazon, traffic, automotive vehicles.

\footnotetext{
1 Instituto Chico Mendes de Conservação da Biodiversidade - ICMBio. Rua Guamá n 23, Floresta Nacional de Carajás, CEP 68516-000. Parauapebas, Pará, Brasil. e-mail: fgumier@gmail.com

2 Universidade Federal de Viçosa. Departamento de Biologia Geral, CEP 36570-000. Viçosa, Minas Gerais, Brasil e-mail: sperber@ufv.br
} 


\section{INTRODUÇÃO}

Vários artigos têm publicado pesquisas sobre o impacto de estradas sobre o ambiente terrestre e até aquático. Estes impactos incluem dispersão de plantas nativas e exóticas, atração e repulsão da fauna, problemas envolvendo drenagem e erosão, poluição do ar com gases e poeira, emissão de ruídos e alteração nos níveis de luminosidade (Forman \& Alexander, 1998). Estradas e rodovias podem causar isolamento e fragmentação de ambientes e forçar populações de animais a cruzá-las. Tal fato aumenta a probabilidade de colisão da fauna com automóveis (Trombulak \& Frissell, 2000).

Estudos sobre atropelamentos de animais silvestres foram realizados na América do Sul (Bencke \& Bencke, 1999; Lima \& Obara, 2006; Rosa \& Mahus, 2004), na Europa (Erritzoe et al., 2003; Seiler, 2001, 2003) e Estados Unidos (Seibert \& Conover, 1991; Aresco, 2005; Smith \& Dodd, 2003). Estes estudos apontam que atropelamentos de animais apresentam padróes relacionados ao tipo de vegetação (florestal, gramíneas e árvores frutíferas), condiçōes climáticas (período seco ou chuvoso) e comportamento das espécies (Pinowski, 2005). Mamíferos de grande e médio porte movem-se ao longo de estradas com pouco tráfego à noite e animais carniceiros deslocam-se por estradas procurando por carcaças (Forman \& Alexander, 1998).

Em trabalho de Pinowski (2005) realizado na Venezuela constatou-se maior incidência de atropelamentos de gambás Didelphis marsupialis (Didelphidae), raposas Cerdocyon thous (Canidae) e serpentes (Ophidia). As mortes de gambás e raposas poderiam estar relacionadas ao hábito carniceiro destes animais. Cobras e lagartos freqüentemente são atraídos pelo asfalto quente especialmente após a chuva e morreriam em conseqüência disto (Bernardino \& Dalrymple, 1992).

Uma crescente literatura (Bencke \& Bencke, 1999; Seibert \& Conover, 1991; Seiler, 2001) sugere que os atropelamentos de animais ocorrem principalmente na estação chuvosa, que está geralmente associada ao período reprodutivo e maior disponibilidade de fontes de alimento como frutas, sementes, flores e outros animais que estimulam o movimento da fauna, aumentando assim a probabilidade desta cruzar estradas e rodovias e conseqüentemente as chances de colisão com automóveis (Forman \& Alexander, 1998; Pinowski, 2005; Smith \& Dodd, 2003).

Alguns trabalhos apontam que atropelamentos de fauna poderiam reduzir a densidade das espécies e colocá-las em risco. Este problema seria mais sério para espécies ameaçadas de extinção ou que normalmente apresentam populaçōes de poucos indivíduos (Forman \& Alexander, 1998; Pinowski, 2005; Trombulak \& Frissel, 2000).

Pesquisas sugerem medidas como corredores, pontes, túneis ou passarelas para animais na tentativa de evitar que estes cruzem as estradas. Também há críticas a estas medidas que poderiam aumentar a taxa de predação ou caça nestas passagens e mais investigaçôes são necessárias (Kirathe \& Parry, 2003; Smith \& Dodd, 2003).

O objetivo geral deste trabalho foi verificar existência de padróes que pudessem explicar os atropelamentos de animais silvestres na Estrada Raimundo Mascarenhas, localizada no interior da Floresta Nacional de Carajás, Pará. Estes padrôes poderiam auxiliar na formulação de estratégias a fim de evitar ou reduzir a mortalidade da fauna. Para tal foram testadas quatro hipóteses: (i) há diferenças entre número de atropelamentos entre trechos da estrada estudada; (ii) há uma alteração na frequêencia de atropelamentos ao longo dos anos amostrados; (iii) alguns táxons são mais freqüentemente atropelados do que outros; e (iv) a freqüência de atropelamentos aumenta com o volume mensal de chuvas.

\section{MATERIAL E MÉTODOS}

\section{ÁREA DE ESTUDO}

A Floresta Nacional de Carajás (FLONA) está localizada no sudeste do estado do Pará, na Amzônia Brasileira. Carajás é uma Unidade de Conservação (UC) Federal gerida pelo ICMBIO (Instituto Chico Mendes de Conservação da Biodiversidade). Esta UC abrange os municípios de Parauapebas, Canaã dos Carajás e Água Azul do Norte e possui área de aproximadamente 400 mil hectares. Carajás é um grande maciço de floresta ombrófila, floresta semi-caducifolia e campos rupestres rodeada por pastagens. Há ainda quatro UCs federais contíguas à FLONA Carajás que são gerenciadas pelo ICMBio e a Terra Indígena (TI) Xicrin do Cateté administrada pela FUNAI (Fundação Nacional do Índio). Estas UCs mais a TI Xicrin totalizam aproximadamente 1,2 milhão de hectares de floresta. Na prática este é um grande refúgio para a vida silvestre e grande testemunho da floresta nativa da regiáo conhecida como "Polígono dos Castanhais" (Figura 1).

A estação chuvosa geralmente começa em novembro e se estende até abril. A estação seca começa em Junho e se estende até Setembro. Maio é um mês de transição do período chuvoso ao seco. Outubro é um mês de transição do período seco ao chuvoso (IBAMA, 2004).

A região também é conhecida como província mineral de Carajás devido às grandes e diversas jazidas minerais. As atividades de mineração da Companhia Vale do Rio Doce (Vale) no interior da Floresta Nacional de Carajás causam intenso movimento de pessoas que trabalham nas minas de ferro $(\mathrm{Fe})$ e manganês $(\mathrm{Mn})$ em operação. $\mathrm{O}$ tráfego de veículos automotores regulado pela Companhia Vale do Rio Doce é de aproximadamente 1352 veículos por dia (Comunicação Pessoal, 2006). O acesso a FLONA é feito pela estrada 


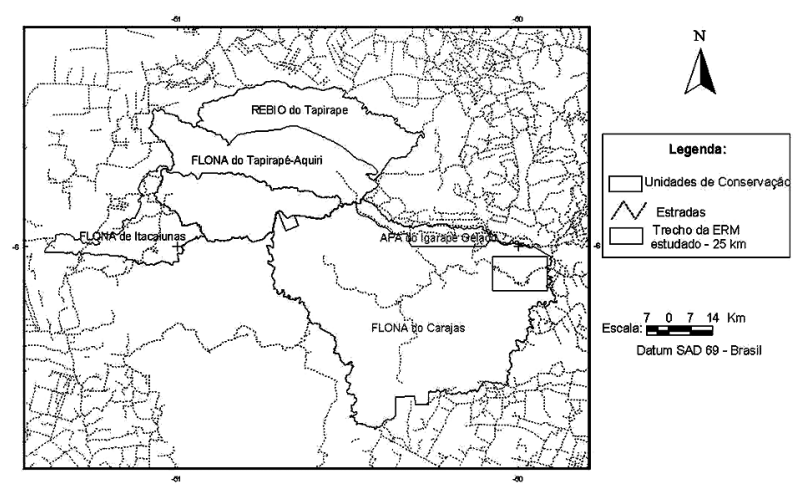

Figura 1 - Localização da área de estudo. No retângulo aparece em destaque 0 trecho de 25 quilômetros da Estrada Raimundo Mascarenhas objeto deste estudo. As linhas tracejadas evidenciam outras estradas da região. 0 mapa da Floresta Nacional de Carajás foi modificado a partir de IBAMA (2004). Siglas: FLONA - Floresta Nacional, APA - Área de Proteção Ambiental e REBIO - Reserva Biológica.

"Raimundo Mascarenhas" (chamada de "estrada" a partir daqui) que é asfaltada em toda sua extensão.

A distância da portaria da FLONA (área urbana de Parauapebas) até o Núcleo Urbano de Carajás é de $25 \mathrm{~km}$ e foi este o trecho da estrada estudado sistematicamente. Nestes 25 $\mathrm{km}$ existem apenas três placas de sinalização sobre fauna. Estas placas estavam instaladas nos quilômetros 14, 15 e 24 .

A Estrada Raimundo Mascarenhas é circundada por Floresta Ombrófila Densa e Aberta desde a portaria da FLONA até o km 33. Daí até o Km 40 encontra-se a área de mina de ferro de N5 e N4, em área campo rupestre conhecida como savana metalófila (Secco \& Mesquista, 1983). Além da estrada existem outros acessos cortando a FLONA e causando acidentes com a fauna.

Para avaliar se houve diferenças na freqüência de atropelamentos entre trechos da estrada, utilizamos três escalas espaciais: na escala maior, utilizamos a distância do início da estrada, em $\mathrm{km}$, até $25 \mathrm{~km}$; numa escala espacial intermediária, dividimos os $25 \mathrm{~km}$ iniciais da estrada em três partes, baseando-se nas suas características físicas: $\mathrm{km} 01$ ao 06 - trechos iniciais da estrada na base da Serra de Carajás com muitas retas, proximidade com o Rio Parauapebas, igarapés e pequenos poços de água onde comumente se avistam antas e capivaras. É possível que neste trecho houvesse maior concentração da fauna e, portanto, com maior probabilidade destes animais cruzarem a estrada e colidirem com automóveis; $\mathrm{Km} 07$ ao 13 - trechos com muita sinuosidade, pouca visibilidade e trechos circundados por abismos de um lado e encostas de morros de outro. Em tese, neste trecho, haveria poucos pontos de travessia de animais e por isso com menor chance de ocorrem atropelamentos; e km 14 ao 25 - topo da serra em um planalto com longas retas rodeadas por áreas planas dos dois lados da estrada sem cursos d’água nas proximidades. A hipótese é que, neste terceiro trecho, similar ao primeiro, haveria maior probabilidade de animais cruzarem a estrada e serem atropelados. Numa escala espacial menor, comparamos a freqüência de atropelamentos entre trechos de $1 \mathrm{~km}$ de comprimento, num total de 25 trechos.

\section{AMOSTRAGEM}

Duas vezes por semana entre abril/2003 e outubro/2006, os primeiros $25 \mathrm{~km}$ da estrada foram percorridos duas vezes por dia (ida e volta), totalizando quatro observações por semana. Todos os animais atropelados foram registrados, incluindo nome comum da espécie, seção da estrada $(\mathrm{km})$, horário e data. Quando era possível parar o carro em local seguro, os animais atropelados foram fotografados.

Os dados pluviométricos para cada mês desde abril de 2003 até outubro de 2006 foram obtidos na estação metereológica do Projeto Salobo (Latitude Sul: 05 48,0'00,0” e Longitude Oeste: 50³0,0' 50,0"; Sistema de Coordenadas GCS South American 1969).

\section{ANÁLISES ESTATÍSTICAS}

Ajustamos modelos lineares generalizados mistos, que foram simplificados pela retirada de termos não-significativos a partir dos modelos completos. Em todos os modelos ajustados, utilizamos a freqüência de atropelamentos como variável resposta. Como a variável resposta foi uma contagem, utilizamos distribuição de erros Poisson (modelos log-lineares). Quando detectada sobre-dispersão, utilizamos a aproximação quasi-Poisson. As análises estatísticas foram realizadas por meio do Software estatístico " $\mathrm{R}$ ” versão 2.6.2 (R Development Core Team, 2008).

Para avaliar a hipótese (i), de que a freqüência de atropelamentos varia entre trechos da estrada, e (ii), de que houve alteração nesta freqüência ao longo dos anos, consideramos o número acumulado de atropelamentos por ano (num total de quatro anos), em cada um das três ou 25 partes da estrada, conforme a escala espacial analisada, como variável resposta, resultando em 100 observaçôes, para as escalas espaciais extremas, de distância do início da estrada ou entre quilômetros, ou em 12 observaçóes, para a escala espacial intermediária, entre trechos da estrada. Para evitar pseudoreplicação (Hurlbert, 1984; Crawley, 2007), incluímos, como efeito aleatório, o trecho da estrada, conforme a escala espacial analisada: para a maior escala espacial, que avaliou o efeito da distância a partir do início da estrada, utilizamos um único grupo aleatório; para a escala intermediária, utilizamos os três trechos, caracterizados acima; para a menor escala espacial, utilizamos os 25 quilômetros como grupos aleatórios. Para as duas maiores escalas espaciais foi possível incluir "ano" como medida repetida, nos efeitos aleatórios do modelo misto (análises de dados longitudinais). Assim, 
para as duas primeiras hipóteses, as análises foram análogas a análises de covariância.

Para avaliar a hipótese (iii), de que alguns táxons são mais freqüentemente atropelados do que outros, consideramos o número acumulado de atropelamentos para cada táxon, por ano, como variável resposta (ANOVAs). Para evitar pseudoreplicação, incluímos "ano" como efeito aleatório de medidas repetidas (análise de dados longitudinais). A variável categórica "táxon" foi ajustada como efeito fixo. Para avaliar a significância das diferenças entre táxons, fizemos análises de contraste, simplificando o modelo completo por retirada passo-a-passo (stepwise deletion), amalgamando os níveis de "táxon", até encontrar o modelo mínimo adequado, em que todos os níveis do fator "táxon" fossem significativos.

Para avaliar a hipótese (iv), de que a freqüência de atropelamentos aumenta com o volume mensal de chuvas, utilizamos o número acumulado de atropelamentos por mês como variável resposta, incluindo mês como fator aleatório de medida repetida (40 meses - análises de dados longitudinais). Não foram coletados dados de atropelamento nos meses de fevereiro, devido a problemas operacionais que impediram o deslocamento da equipe. Assim, omitimos das análises os dados de fevereiro para os anos de 2004 a 2006, resultando em 40 meses, de abril de 2003 a outubro de 2006. Ajustamos modelos lineares generalizados mistos, com a seqüência cronológica de mês como medida repetida, e um grupo único como efeito aleatório categórico. A única variável resposta nestas análises foi a precipitação mensal (regressão linear). Para discutirmos os resultados avaliamos a variação sazonal da precipitação.

\section{RESULTADOS}

Encontramos um total de 155 espécimes atropelados ao longo deste estudo (Tabela 1). Em números absolutos, os táxons mais afetados foram serpentes, gambás, aves, raposas, quatis e pequenos roedores. Ocorreu uma redução no número de atropelamentos ao longo dos anos $(\mathrm{P}=0,01)$ (Tabela 1 , Figura 2), e com a distância de Parauapebas $(P=0,0002)$ (Figura 3). No entanto, não houve diferença no número de atropelamentos nas escalas espaciais menores, entre as três partes $(\mathrm{P}=0,69)$ (Figura 4) ou entre os quilômetros $(\mathrm{P}=$ 0,86 ) (Figura 5).

Houve quatro grupos de vertebrados com diferentes freqüências de atropelamento $(\mathrm{P}<0,0001)$ (Figura 6). Serpentes (Ophidia) e gambás Didelphis marsupialis foram os táxons com maior freqüência de atropelamentos (média de 7,5 indivíduos por ano, para cada táxon, código "cf" na Figura 6). O segundo conjunto de táxons mais freqüentemente atropelados foram aves, raposas Cerdocyon thous, quatis Nasua nasua, roedores (Rodentia), e animais não identificados (média de 4,9 indivíduos por ano, código "amnor" na Figura
Tabela 1 - Vertebrados atropelados na estrada "Raimundo Mascarenhas" desde abril de 2003 até outubro de 2006.

\begin{tabular}{|c|c|c|c|c|c|c|}
\hline Nome Comum & Nome científico & 2003 & 2004 & 2005 & 2006 & Total \\
\hline Serpentes & Ophidia & 8 & 7 & 9 & 7 & 31 \\
\hline Gambá & $\begin{array}{l}\text { Didelphis } \\
\text { marsupialis }\end{array}$ & 10 & 11 & 3 & 5 & 29 \\
\hline Não identificado & & 10 & 7 & 5 & 3 & 25 \\
\hline Aves & Aves & 7 & & 3 & 6 & 16 \\
\hline Quati & Nasua nasua & 3 & & 4 & 4 & 11 \\
\hline Raposa & Cerdocyon thous & 5 & & 3 & 3 & 11 \\
\hline Roedores & Rodentia & 4 & 6 & & & 10 \\
\hline Mico & Saguinus sp. & & 4 & & & 4 \\
\hline $\begin{array}{l}\text { Tamanduá- } \\
\text { mirim, } \\
\text { mambira }\end{array}$ & Tamandua tetradac & ctyla & 1 & 2 & 1 & 4 \\
\hline Cotia & $\begin{array}{l}\text { Dasyprocta } \\
\text { agouti }\end{array}$ & 2 & & 1 & & 3 \\
\hline Preguiça & $\begin{array}{l}\text { Choloepus } \\
\text { didactylus }\end{array}$ & 1 & & 1 & 1 & 3 \\
\hline Jabuti & Geochelone sp. & 1 & & 1 & & 2 \\
\hline Cuíca, catita & Marmosops sp & & & & 1 & 1 \\
\hline Tapeti & $\begin{array}{l}\text { Sylvilagus } \\
\text { brasiliensis }\end{array}$ & 1 & & & & 1 \\
\hline $\begin{array}{l}\text { Guariba, bugio, } \\
\text { capelão }\end{array}$ & Alouatta sp. & & 1 & & & 1 \\
\hline Irara, papa-mel & Eira barbara & & & & 1 & 1 \\
\hline Lagartos & Lacertilia & 1 & & & & 1 \\
\hline Macaco prego & Cebus apella & 1 & & & & 1 \\
\hline TOTAIS & & 54 & 37 & 32 & 32 & 155 \\
\hline
\end{tabular}

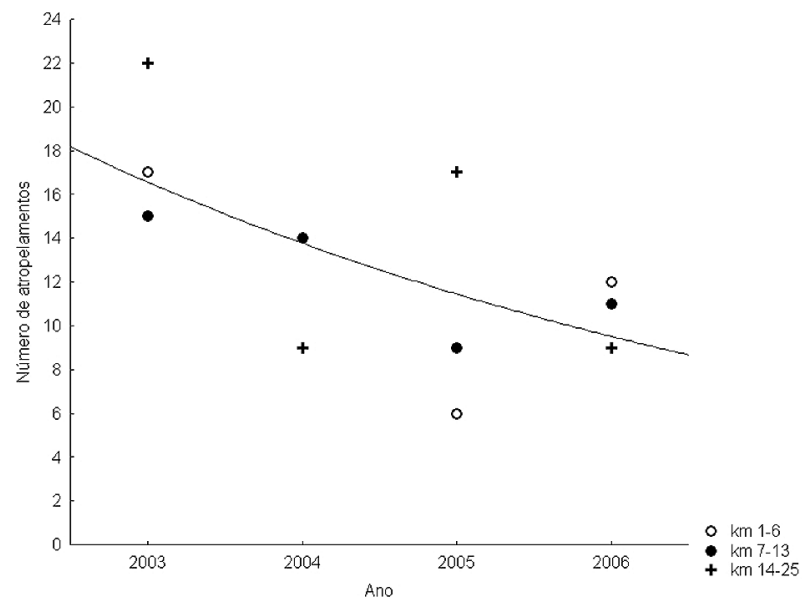

Figura 2 - Número de atropelamentos de vertebrados por trecho da estrada, ao longo dos anos. Modelo misto de regressão log-linear para medidas repetidas, com "trecho da estrada" como efeito aleatório e "ano" como medida repetida; número de observações $=12$; número de grupos $=3 ; \mathrm{P}=0,01$; $\mathrm{Y}=\exp (373,36258-0,18500 \star \mathrm{X})$. 


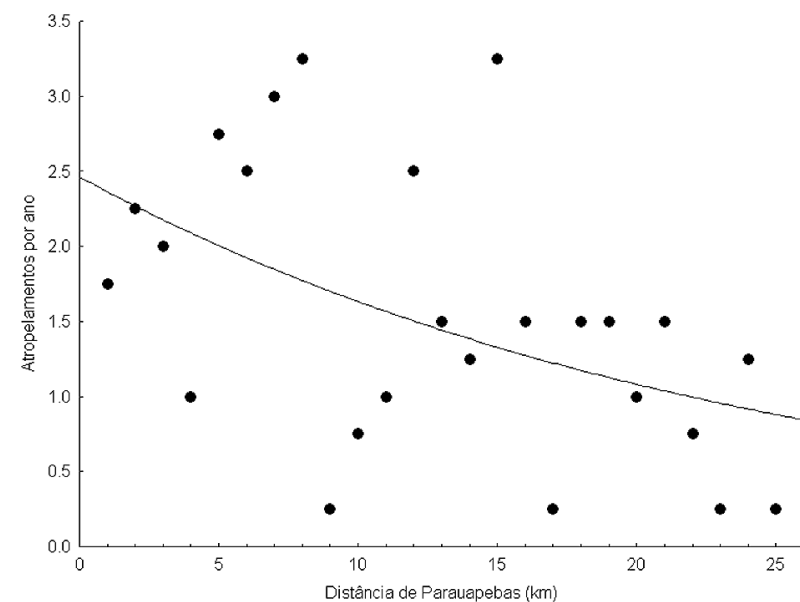

Figura 3 - Número de atropelamentos de vertebrados por ano, em função da distância do início da estrada (município de Parauapebas). Modelo misto de regressão log-linear para medidas repetidas, com "trecho da estrada (quilômetro)" como efeito aleatório e "ano" como medida repetida; número de observações $=100$; número de grupos $=25$; "ano" e "distância" foram significativos $(P<0,05)$; curva representa a média entre anos; $\mathrm{Y}=\exp (371,73382-0.04374 * \mathrm{X}-0,18501 * a n 0)$.

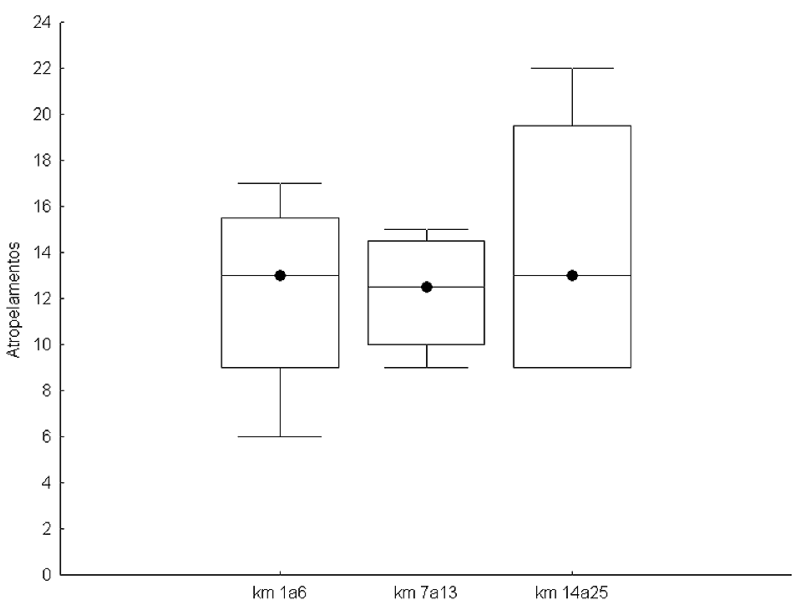

Figura 4 - Box-plot do número de atropelamentos de vertebrados por ano, em função do trecho da estrada (quilometragem a partir de Parauapebas). Pontos = mediana; caixa $=25 \%$ a $75 \%$ dos dados; barras = non-outlier range. Não houve diferença significativa no número de atropelamentos entre trechos.

6). Os táxons menos atropelados foram cuíca Marmosops sp., tapeti Sylvilagus brasiliensis, guariba Alouatta sp., irara Eira barbara, jabuti Geochelone sp., lagartos (Lacertilia) e macaco prego Cebus apella, com apenas 1 indivíduo de cada grupo atropelado por ano.

Entre as espécies de cobras foram identificadas Boa constrictor, Epicrates sp., Spilotes pullatus, Eunectes sp. e várias espécies não identificadas da família Colubridae. Não foi possível identificar as espécies de aves em virtude do

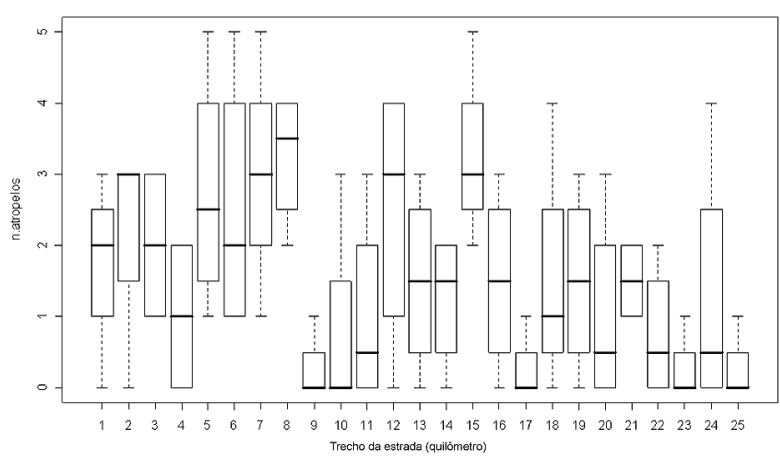

Figura 5 - Box-plot do número de atropelamentos de vertebrados por ano (n. atropelos), em função do trecho da estrada (quilômetro). Linhas grossas = mediana; caixa $=25 \%$ a $75 \%$ dos dados; barras $=$ non-outlier range. Não houve diferença significativa no número de atropelamentos entre trechos.

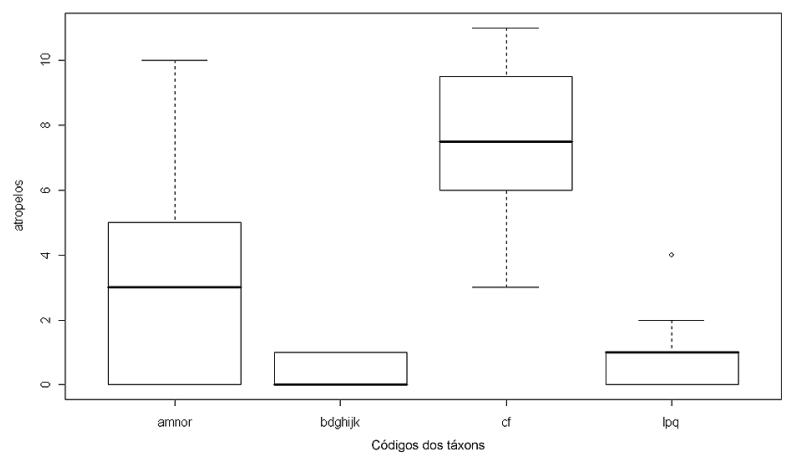

Figura 6 - Box-plot do número de atropelamentos de vertebrados por ano (atropelos), para os quatro grupos de táxons com taxas significativamente diferentes de atropelamentos $(P=0.01)$. Códigos dos táxons: "amnor" = Aves, quati, Cerdocyon thous, Nasua nasua, Rodentia e animais não identificados; "bdghijk" = Marmosops sp., Sylvilagus brasiliensis, Alouatta sp., Eira barbara, Geochelone sp., Lacertilia e Cebus apella; "cf" = Ophidia e Didelphis marsupialis; "Ipq" = Choloepus didactylus, Saguinus sp., Tamandua tetradactyla. Linhas grossas = mediana; caixa $=25 \%$ a $75 \%$ dos dados; barras $=$ non-outlier range; círculos $=$ outliers. 0 gráfico representa o modelo mínimo adequado, após simplificação de ANOVAs log-lineares mistas para medidas repetidas, com "ano" como medida repetida e "estrada" como grupo aleatório; número de observações $=72$.

esmagamento da carcaça dos animais. O mesmo aconteceu com as espécies de pequenos roedores e lagartos.

Embora a precipitação mensal tenha apresentado variação sazonal (Figura 7), com maiores índices pluviométricos entre novembro e março nos quatro anos estudados, não houve relação significativa entre o número mensal de atropelamentos e a precipitação mensal $(\mathrm{P}=0,11$; Figura 8$)$. 


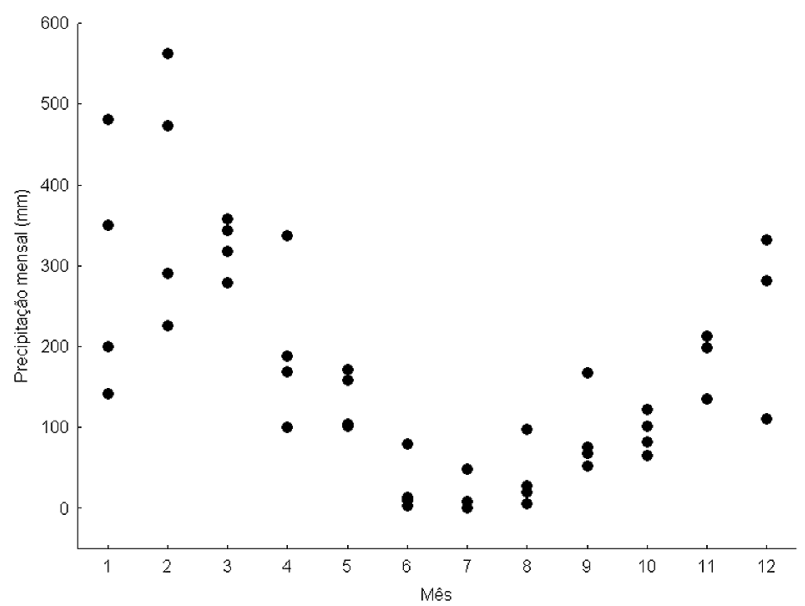

Figura 7 - Precipitação mensal nos quatro anos estudados (2003 a 2006), em função do mês ( 1 = janeiro, 2 = fevereiro etc.).

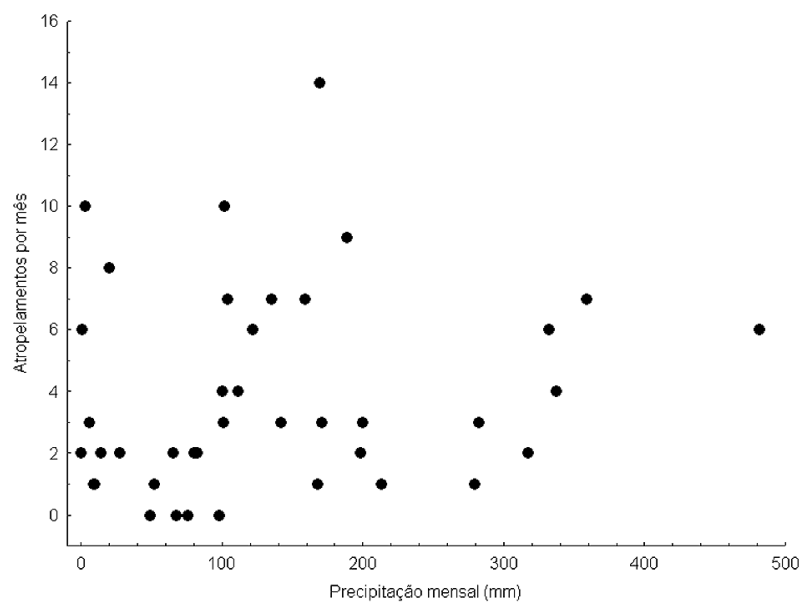

Figura 8 - Número de atropelamentos por mês em função da precipitação mensal. Modelo misto de regressão log-linear para medidas repetidas, com tempo (meses) como medidas repetidas e "estrada" como grupo aleatório; número de observações $=40 ; P=0,10$ ).

\section{DISCUSSÃO}

Apesar de termos detectado um número alto de atropelamentos ao longo deste estudo, este valor pode ser subestimado, devido à remoção de carcaças frescas, particularmente por funcionários de instituiçōes interessadas em minorar a magnitude deste impacto. Acreditamos que a redução de atropelamentos entre 2003 e 2006 seja um fruto, inesperado, de ações de sensibilização realizadas pela equipe do IBAMA (atual ICMBio) junto à empresa mineradora Vale®. A partir desta sensibilização, passaram a ocorrer açōes policiais esporádicas na Estrada Raimundo Mascarenhas, pelas Polícias Rodoviárias Federal e Estadual e pelo Departamento de Trânsito de Parauapebas (DMTT), e fiscalizaçōes mais regulares pela segurança patrimonial da Vale®. Mesmo que estas campanhas de trânsito não tenham sido centradas em proteção da fauna, e sim em segurança no trânsito e riscos à vida humana, acreditamos que isto tenha se refletido em redução na frequiência de atropelamentos e dos impactos sobre a fauna silvestre. Há que se ter cautela na extrapolação da redução dos atropelamentos, uma vez que há planos de ampliação em larga escala dos projetos de mineração na área, o que deverá acarretar em substancial aumento no fluxo de veículos, e aumento na freqüência de atropelamentos.

A redução de atropelamentos com a distância da cidade de Parauapebas pode ser devida ao distanciamento de cursos d'água, abundantes no início da estrada. Se esta hipótese for verdadeira, espera-se que a densidade de fauna silvestre seja maior no início da estrada (quilômetro zero), diminuindo com a distância.

A ausência de diferenças nas freqüências de atropelamentos entre trechos da estrada, nas duas menores escalas espaciais, foi contrária à nossa expectativa. Esperávamos encontrar trechos específicos da estrada com taxas significativamente maiores de atropelamentos, como detectado em outras estradas (Forman \& Alexander 1998). Tais trechos apontam partes da estrada onde seria recomendada a construção de corredores, túneis, eco-passagens ou pontes e passarelas para travessia da fauna (Kirathe \& Parry, 2003; Seiler 2001, 2003; Smith \& Dodd, 2003). Não identificamos nenhum trecho como especialmente apropriado para a construção de passagens, porém nossos resultados mostram que algum trecho na região inicial da estrada seria mais adequado para isto.

É preciso considerar que a construção de passagens para a fauna, apenas por sua instalação, já causa distúrbios e, no caso da estrada estudada, poderia não funcionar por falta de uso pela fauna. Barreiras, como cercas ao longo dos trechos sem passarela, poderiam direcionar a fauna para as passarelas, mas também poderiam isolar ou dividir populaçōes causando um distúrbio muito grande.

Muitos trabalhos citam grande mortalidade de gambás Didelphis spp, raposas Cerdocyon thous e serpentes, por colisão com automóveis (Pinowski, 2005; Rosa and Mauhs, 2004; Smith \& Dodd, 2003). As espécies de marsupiais Philander opossum e Didelphis spp. são citadas como dispersoras de sementes de embaúba Cecropia obtusifolia (Cecropiaceae) (Fournier, 2003; Medellin, 1994). Nas laterais da estrada nota-se a vegetação alterada pelos efeitos de borda com muitas espécies pioneiras como as Cecropiaceae. Este fato pode explicar a grande mortalidade de gambás que forrageiam na borda da estrada e freqüentemente a atravessam. Raposas são predadoras e carniceiras e se movem intensamente ao longo de estradas, procurando presas ou outros animais mortos por atropelamento. Nossos resultados são similares a outros presentes na literatura, que mostram grande número de predadores nas margens de estradas (Pinowski, 
2005; Scoss, 2004; Smith \& Dodd, 2003; Rosa \& Mauhs, 2004). Outros estudos reportam grande número de cobras e lagartos mortos por atropelamento. Isto ocorre porque estes animais usualmente procuram o asfalto aquecido após chuvas (Bernardino \& Dalrymple, 1992; Pinowski, 2005). O quati Nasua nasua (Procyonidae) é uma espécie abundante na região, que vive e se desloca sempre em grandes grupos e estes constantemente cruzam as estradas.

Como a estrada aqui estudada atravessa a Floresta Nacional de Carajás e outras Unidades de Conservação da regiāo, que são refúgios naturais para a fauna, que sofre fortes impactos do desmatamento e queimadas em todo o sudeste do Pará, a perda de indivíduos por atropelamentos pode ter grande impacto na conservação biológica.

Os atropelamentos de animais de locomoção lenta, como preguiças e jabutis, evidenciam como os motoristas são pouco sensíveis ao problema, pois para vertebrados lentos, seria possível desviar-se ou reduzir a velocidade, evitando o atropelamento. Este problema poderia ser reduzido pela instalação de placas de sinalização, específicas para a fauna, associada a campanhas educativas, e inserção de redutores de velocidade e sonorizadores, especialmente nas longas retas. Especialmente em tais trechos, é comum encontrarmos veículos ultrapassando a velocidade de $120 \mathrm{~km} / \mathrm{h}$, apesar da velocidade máxima permitida ser de $80 \mathrm{~km} / \mathrm{h}$. Campanhas educativas também podem contribuir para a redução de atropelamentos.

A ausência de correlação entre precipitação mensal e freqüência de atropelamentos é contrasta com trabalhos similares, que apontam correlação positiva entre precipitação e atropelamentos (Forman \& Alexander, 1998; Pinowski, 2005; Smith \& Dodd, 2003). A falta de dados de nosso trabalho sobre atropelamentos em fevereiro, o mês mais chuvoso, e os meses de início do período chuvoso (novembro e dezembro) de 2006, pode ser a responsável pela ausência de significância de nossos resultados. Uma eventual correlação significativa entre frequiência de atropelamentos e precipitação mensal pode se dever à sincronização de floração e frutificação de várias espécies vegetais utilizadas como recursos pela fauna silvestre, levando a uma maior atividade e movimentação da fauna. Por outro lado, chuvas em excesso podem obrigar os motoristas a reduzirem a velocidade, reduzindo a probabilidade de atropelamentos da fauna, o que anularia o efeito de maior disponibilidade de recursos.

Em geral os resultados do presente estudo auxiliam na compreensão dos padrōes determinantes dos atropelamentos de vertebrados silvestres na região de Carajás e mostram que medidas mitigadoras precisam ser executadas. $\mathrm{O}$ monitoramento destes atropelamentos de vertebrados deve continuar e pretende-se avaliar se diferenças na tipologia da vegetação junto à estrada, como espécies frutíferas atrativas de fauna e outras variaçóes na paisagem, como cursos de água, interferem na freqüência de atropelamentos. Também é importante testar o efeito de algumas intervenções, como corte seletivo de espécies vegetais atrativas, o que pode reduzir a densidade da fauna na margem da estrada. Do mesmo modo, é importante verificar a viabilidade de galerias ou túneis para passagem de fauna em alguns pontos, considerando a frequêencia de utilização pela fauna e possíveis incrementos de taxa de predação. Em caso de adoção de alguma intervenção desta natureza, é importante monitorar a caça, dada a possibilidade de conduta oportunista de caçadores nestes locais.

\section{AGRADECIMENTOS}

Os autores são gratos a Simone Gumier Costa pela revisão do resumo em Inglês, a Orlando Vieira e empresa Salobo Metais S. A. pelo fornecimento dos dados de precipitação de chuvas da estação metereológica da empresa, aos colegas do IBAMA Amarílio Coutinho Fernandes, Raimundo Façanha Guedes, Leo Bento, Viviane Lasmar P. Monte, Leonardo Brasil M. Nunes e Orlando Alves Maia pela colaboração na coleta de dados sobre atropelamentos de animais silvestres na Estrada Raimundo Mascarenhas e aos revisores desta revista pelos preciosos comentários.

\section{BIBLIOGRAFIA CITADA}

Aresco, M.J. 2005. The effect of sex-specific terrestrial movements and roads on the sex ratio of freshwater turtles. Biological Conservation, 123: 37-44.

Bencke, G.A.; Bencke, C.S.C. 1999. The potential importance of road deaths as cause of mortality for large forest owls in southern Brazil. Cotinga, 11: 79-80.

Bernardino Jr., F.S.; Dalrymple, G.H. 1992. Seazonal activity and road mortality of the snakes of the Pa-hay-okee wetlands of Everglades National Park, USA. Biological Conservation, 62: $71-75$.

Crawley, M.J. 2007. The R book. John Wiley, Chichester, 942pp.

Erritzoe, J.; Mazgajski, T.D.; Rejt, L. 2003. Bird casualties on European roads - a review. Acta Ornithologica, 38 (2): 77-93.

Forman, R.T.T.; Alexander, L.E. 1998. Roads and their major ecological effects. Annu. Rev. Ecol. Syst., 29: 207-231.

Fournier, L.A. 2006. Cecropia obtusifolia Bertol. The RNGR Team: Reforestation, Nurseries and Genetics Resources. Disponível em http://www.rngr.net/Publications/ttsm/Folder.2003-0711.4726/PDF.2003-12-08.1432/view. Acesso em 16/11/2006.

Hurlbert, S.H. 1984. Pseudoreplication and the design of ecological field experiments. Ecological Monographs, 54: 187-211.

Instituto Brasileiro do Meio Ambiente e dos Recursos Naturais Renováveis (IBAMA). 2004. Plano de Manejo para Uso Múltiplo da Floresta Nacional de Carajás. Brasília, DF, Brasil.

Kirathe, J.N.; Parry, L.T.W. 2003. The use of Elevated RoadSpanning Ladders by Primates in Diani, Kenya. Wakuluzu: 
Friends of the Colobus Trust. Disponível em http://www. colobustrust.org/programmes/colobridges_report.html. Acesso em 16/11/2006.

Lima, S.F.; Obara, A.T. 2004. Levantamento de Animais silvestres atropelados na BR-277 às margens do Parque Nacional do Iguaçu: Subsídios ao programa multidisciplinar de proteção à fauna. VII Semana de Artes da Universidade Estadual de Maringá. Disponível em http://www.pec.uem.br/dcu/VII_SAU/ sau_trabalhos_6_laudas.htm. Acesso em 10/11/2006.

Medellin, R.A. 1994. Seed Dispersal of Cecropia obtusifolia by Two Species of Opossums in the Selva Lacandona, Chiapas, Mexico. Biotropica, 26 (4): 400-407.

Pinowski, J. 2005. Roadkills of Vertebrates in Venezuela. Revista Brasileira de Zoologia, 22(1): 191-196.

R Development Core Team. 2008. R: A Language and Environment for Statistical Computing. R Foundation for Statistical Computing. Vienna, Austria. ISBN: 3-900051-07-0. Disponível em http:// www.R-project.org. Acesso em Apr.-Sep./2008.

Rosa, A.O.; Mahus, J. 2004. Atropelamentos de animais silvestres na rodovia RS-040. Caderno de Pesquisa série Biologia, 16(1): $35-42$.
Secco, R.S.; Mesquita, A.L. 1983. Nota sobre a vegetação de canga da Serra Norte. Boletim do Museu Paraense Emílio Goeldi. Nova Série Botânica, 59: 1-13.

Scoss, L.M.; de Marco Jr. P.; Silva, E.; Martins, S.V. 2004. Uso de parcelas de areia para o monitoramento de impacto de estradas sobre a riqueza de espécies de mamíferos. Revista Arvore, 28(1): 121-127.

Seibert, H.C.; Conover, J.H. 1991. Mortality of Vertebrates and Invertebrates on an Athens County, Ohio, Highway. Ohio Journal of Science, 91(4): 163-166.

Seiler, A. 2001. Ecological Effects of roads - a review. Department of Conservation Biology, Swedish University of Agricultural Sciences, Introductory Research Essay 9, Uppsala, Sweden.

Seiler, A. 2003. The toll of the automobile: Wildlife and roads in Sweden. Thesis, Swedish University of Agricultural Sciences, Uppsala, Sweden.

Smith, L.L.; Dodd Jr, C.K. 2003. Wildlife mortality on U.S. highway 441 across paynes prairie, Alachua County, Florida. Florida Scientist, 66(2): 128-140.

Trombulak, S.C.; Frissell, C.A. 2000. Review of Ecological Effects of Roads on Terrestrial and Aquatic Communities. Conservation Biology, 14(1): 18-30.

Recebido em 15/10/2008

Aceito em 06/02/2009 